\title{
Leonardo Da Vinci (1452-1519) and reproductive anatomy
}

\author{
Peter M Dunn
}

\author{
"Science comes by observation, not by \\ authority"
}

Leonardo was born on 15 April 1452, the illegitimate son of Ser Piero, a Florentine lawyer, and Caterina, the maid at an inn in Vinci, a village in the foothills of Albana in Tuscany. Claimed by his father at the age of 4 , he grew up in Florence and was apprenticed to the sculptor and painter, Andrea Verrocchio, in 1469. In 1472 he was registered as a master craftsman in the Guild of St Luke. Thus began the career of a man whose intellect and talent have never been surpassed. Artist, scientist, inventor, visionary and philosopher, Leonardo sought to unravel all the mysteries of life and the universe. ${ }^{1-2} \mathrm{He}$ took all knowledge as his provence.

His patrons included Lorenzo de Medici, Ludovico Sforza, Popes Alexander VI and Julius II, and Francis I of France. Working mostly in Florence, Milan, and Rome over the next 45 years, he remained single as well as single-minded in his search for the truth (fig 1). As he wrote: "If you are alone you belong entirely to yourself. If you are accompanied even by one companion you belong only half to yourself, or even less in proportion to the thoughtlessness of his conduct ... Concentration of the mind comes by solitude."

Although the Church strictly forbade post mortem dissection, Leonardo determined to study human anatomy, including the relation between structure and function. ${ }^{3}$ Between 1489 and 1513, often working by candlelight in the crypt of a church, he painstakingly dissected "more than 30 bodies, both of men and women of all ages." He described how others "...might be deterred by the fear of living in the night hours in the company of these corpses, quartered and flayed and horrible to see."

His remarkable powers of observation, his knowledge of perspective and his skill in drawing enabled him to record his findings with amazing accuracy and clarity, especially considering the difficulties under which he was working, and that he was pioneering what was virtually a new field. Sadly, he did not receive just credit, for his anatomical drawings, several hundred in number, were not widely known until some 380 years after his death when they were first published in facsimile. In retrospect,

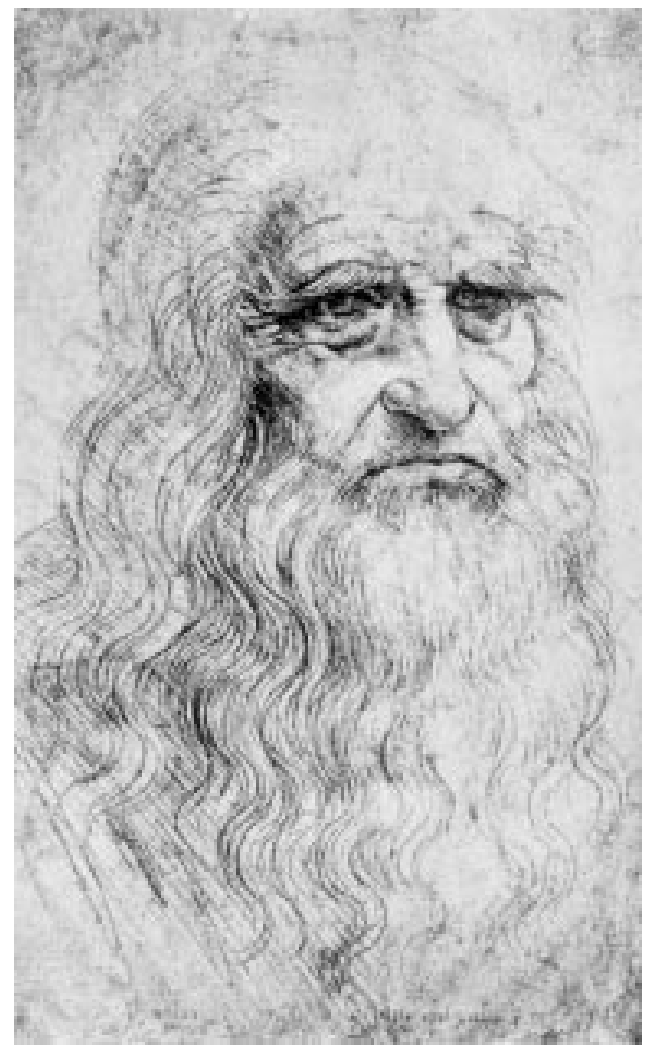

Figure 1 Leonardo da Vinci, 1452-1519. Self portrait in old age.

he was arguably the greatest anatomist of all time. He can also be said to have pioneered the future sciences of morbid anatomy and forensic medicine with his classic description of coronary heart disease as a cause of death in 1506 :

"An old man, only a few hours before he died, told me that he had lived for one hundred years without experiencing any physical failure other than weakness; and sitting on the bed in the hospital of Santa Maria Nova in Florence, he passed from this life, giving no sign of any accident. And I dissected his body, in order to understand the cause of so easy a death. I discovered that it came to him through a lack of blood in the arteries that fed the heart and the lower parts, which were used up and dried out." 
Leonardo wrote a memorandum on how the book "Of the Human Figure" that he and the anatomist Marc Antonio Della Torre planned to write, should be presented. Unfortunately, Torre died prematurely aged 29 and their book was never published:

"This work must begin with the conception of man, and describe the nature of the womb and how the foetus lives in it, up to what stage it resides there, and in what way it quickens into life and feeds. Also its growth and what interval there is between one stage of growth and another. What it is that forces it out from the body of the mother, and for what reasons it sometimes comes out of the mother's womb before the due time. Then I will describe which are the members, which, after the boy is born, grow more than the others, and determine the proportions of a boy of one year. Then describe the fully grown man and woman, with their proportions, and the nature of their complexions, colour, and physiognomy. Then how they are composed of veins, tendons, muscles and bones ... And three (perspective drawings) you must have for the woman, in which there is much that is mysterious by reason of the womb and the foetus..."

In this brief article interest must focus on Leonardo's study of reproductive anatomy and physiology:

"Your order shall commence with the formation of the child in the womb, saying which part of it is formed first and so on in succession, placing its parts according to the times of pregnancy until the birth, and how it is nourished, learning in part from the eggs which hens make."

Leonardo drew the reproductive organs of both men and women and also illustrated coitus (fig 2). He was the first to observe and comment on the fetal membranes-the chorion, amnion, and allantois. His drawing of a fetus in the womb (fig 3) is altogether remarkable and was not bettered for more than two centuries. Of that drawing, he wrote:

"In the case of this child the heart does not beat and it does not breathe because it lies continually in water. And if it were to breathe it would be drowned, and breathing is not necessary to it because it receives life and is nourished from the life and food of the mother."

He added:

"The navel is the gate from which our body is formed by means of the umbilical vein... This umbilical vein is the origin of all the veins of the creature that is produced in the matrix, and it does not take its origin in any vein of the pregnant woman, because each of these veins is entirely separated and divided from the veins of the pregnant woman, and the veins and arteries are found together in pairs; and it is extremely rare for one to be found without the other being in company

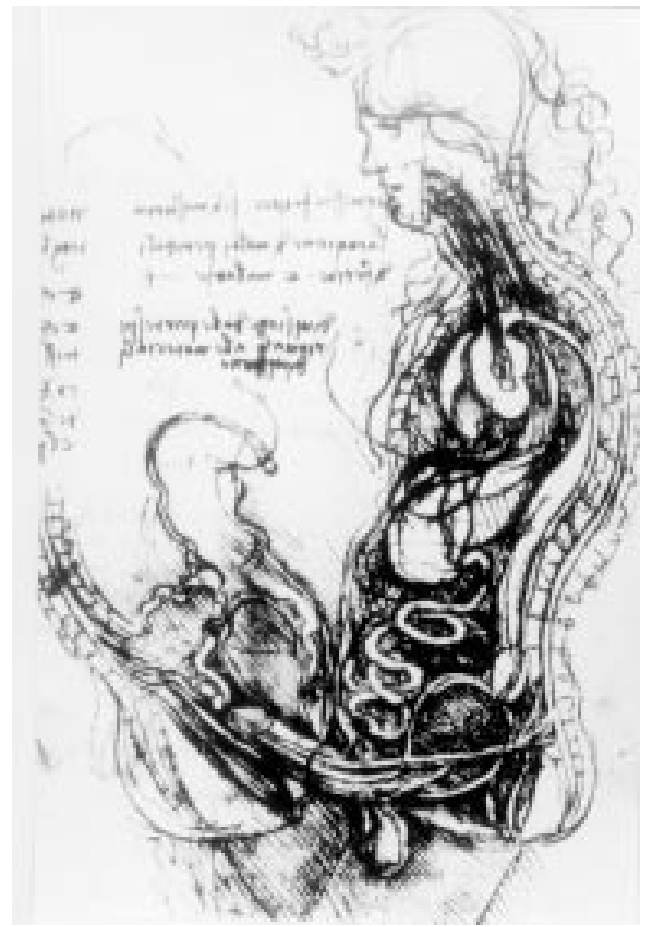

Figure 2 Coitus.

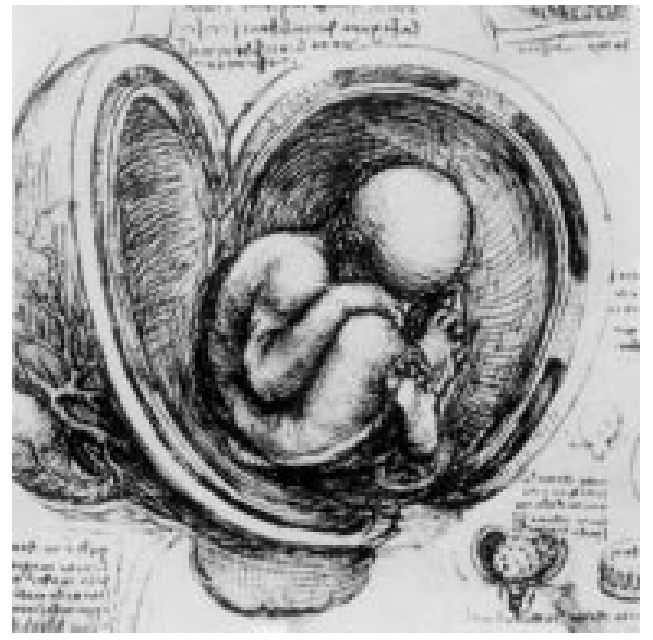

Figure 3 Fetus in utero, circa 1505.

with it, and the artery is almost always found above the vein because the blood of the artery is the passage for the vital spirit, and the blood of the veins is that which nourishes the creature.... (the unborn child) is nourished from the same cause as the other members of the mother, and its vital powers are derived from the air which is the common living principle of the human race and other living things."

In appreciating that the maternal and feto-placental vasculatures did not communicate, Leonardo in part anticipated the discovery of the two separate circulations made by William Harvey (1651) and William Hunter (1774).

Leonardo's observation on the inheritance of skin colour is also of great interest: 
"The black races of Ethiopia are not the product of the sun; for if black gets black with child in Scythia, the offspring is black; but if a black gets a white woman with child the offspring is grey. And this shows that the seed of the mother has power in the embryo equally with that of the father."

Leonardo did not have a high opinion of the doctors of his day. He wrote:

"Strive to preserve your health; and in this you will the better succeed in proportion as you keep clear of the physicians, for their drugs are a kind of alchemy concerning which there are no fewer books than there are medicines ... You know that medicines when well used restore health to the sick: they will be well used when the doctor together with his understanding of their nature shall understand also what man is, what life is, and what constitution and health are. Know these well and you will know their opposites; and when this is the case you will know well how to devise a remedy."

He believed strongly in health care. His instructions have a remarkably modern ring:

"If you would keep healthy, follow this regimen: do not eat unless you feel inclined, and sup lightly; chew well, and let what you take be well cooked and simple. He who takes medicine does himself harm; do not give way to anger and avoid close air; hold yourself upright when you rise from table and do not let yourself sleep at midday. Be temperate with wine, take a little frequently, but not at other than the proper meal-times, not on an empty stomach; neither protract nor delay the (visit to) the privy. When you take exercise let it be moderate. Do not remain with the belly recumbent and the head lowered, and see that you are well covered at night. Rest your head and keep your mind cheerful; shun wantonness, and pay attention to diet."

In 1516, Francis I invited Leonardo to France where he lived in the Manor of Cloux near Amboise. But his health was failing and on 2 May 1519 he died. Benvenuto Cellini recorded Francis' tribute to him:

"He did not believe that any other man had come into the world who had attained so great knowledge as Leonardo, and that not only as sculptor, painter, and architect, far beyond that he was a profound philosopher."

Leonardo was buried in the Church of St Florentin in Amboise. He might be said to have written his own epitaph with these words: "As a well-spent day brings happy sleep, so life well used brings happy death.”

1 MacCurdy E. The notebooks of Leonardo da Vinci. Vols 1-3. London: Reprint Society, 1954

2 Buhrer EM, ed. The unknown Leonardo. London: Hutchison and Co, 1974.

3 Mathé J. Leonardo da Vinci: anatomical drawings. Translated by D Macrae. Fribourg: Productions Liber S A CH, 1984. 